\title{
Early maternal separation accelerates the progression of endometriosis in adult mice
}

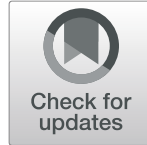

Qiqi Long ${ }^{1 \dagger}$, Xishi Liu ${ }^{1,2+}$ and Sun-Wei Guo $0^{1,2,3^{*}}$ (D

\begin{abstract}
Background: A large body of research highlights the importance of early-life environmental impact on the health outcome in adulthood. However, whether early-life adversity (ELA) has any impact on the development of endometriosis is completely unclear. In this study, we tested the hypothesis that ELA, as manifested by neonatal separation, can accelerate the progression of endometriosis in mouse through activation of the adrenergic receptor $\beta 2$ (ADRB2) signaling pathway, leading to increased angiogenesis and progression of endometriotic lesions.

Methods: Eight female Balb/C mice, in late pregnancy, were used used for this study, which later gave birth to 22 female newborn pubs. Eleven additional female Balb/C mice were also used as donors of uterine tissues. The 22 newborn pubs were randomly divided into 2 equal-sized groups, maternal separation (MS) and no separation (NS). Pubs in the MS group were separated from their dams for $3 \mathrm{~h} /$ day from postnatal day (PND) 1 to 21 , while those in the NS control remained in the home cage with their dams. In adulthood (8-week old), 3 mice in each group were randomly selected to undergo a battery of behavior tests. The remaining 8 mice in each group were induced with endometriosis by intraperitoneal injection of uterine fragments from donor mice. Four weeks after the induction, all mice were sacrificed and their endometriotic lesions were excised for quantification and then prepared for immunohistochemistry analysis.

Results: We confirmed that MS during infancy resulted in anxiety and depression-like behaviors as previously reported. We also found that in MS mice the lesion weight was increased by over 2 folds and generalized hyperalgesia was also significantly increased as compared with NS mice. Immunostaining analysis demonstrated that MS accelerated the development of endometriosis likely through decreased dopamine receptor D2 (DRD2) expression and activation of the ADRB2/CAMP-response element binding protein (CREB) signaling pathway, leading to increased angiogenesis and progression of endometriotic lesions.

Conclusions: Exposure of female mouse pups to ELA such as MS during their infancy period accelerates the progression of endometriosis, possibly through altered neuronal wiring and hyperactivity of the hypothalamicpituitary-adrenal axis.
\end{abstract}

Keywords: Adrenergic receptor, Early life adversity, Endometriosis, Maternal separation, Mouse

\footnotetext{
* Correspondence: hoxa10@outlook.com

${ }^{\dagger}$ Qiqi Long and Xishi Liu contributed equally to this work.

'Shanghai Obstetrics and Gynecology Hospital, Fudan University, Shanghai 200090, China

${ }^{2}$ Shanghai Key Laboratory of Female Reproductive Endocrine-Related Diseases, Fudan University, Shanghai, China

Full list of author information is available at the end of the article
}

(c) The Author(s). 2020 Open Access This article is licensed under a Creative Commons Attribution 4.0 International License, which permits use, sharing, adaptation, distribution and reproduction in any medium or format, as long as you give appropriate credit to the original author(s) and the source, provide a link to the Creative Commons licence, and indicate if changes were made. The images or other third party material in this article are included in the article's Creative Commons licence, unless indicated otherwise in a credit line to the material. If material is not included in the article's Creative Commons licence and your intended use is not permitted by statutory regulation or exceeds the permitted use, you will need to obtain permission directly from the copyright holder. To view a copy of this licence, visit http://creativecommons.org/licenses/by/4.0/ The Creative Commons Public Domain Dedication waiver (http://creativecommons.org/publicdomain/zero/1.0/) applies to the data made available in this article, unless otherwise stated in a credit line to the data. 


\section{Introduction}

Endometriosis, characterized by the ectopic presence and growth of functioning endometrial tissues, is a disease affecting $6-10 \%$ of women of reproductive age [1]. Despite its high prevalence and debilitating nature impacting negatively on the quality of life in women afflicted with the disease [2], its pathogenesis is still poorly understood, and few, if any, modifiable risk factors have been identified [3].

In the last three decades, a large body of research highlights the importance of early-life environmental impact on the health outcome in adulthood. Notably, the hypothesis of "developmental origin of adult health and disease" $(\mathrm{DOHaD})$ was proposed, which posits that unfavorable environmental early-life conditions can lead to "developmental programming" in later life and the subsequent modification in risks of many chronic diseases [4-6]. Initially concerned with the impact of prenatal and neonatal malnutrition on adult health, the hypothesis has received empirical support from epidemiological studies worldwide. Over the years, however, it became evident that non-nutritional, early-life adversity (ELA), such as abuse, neglect and traumatic events, also can have long-lasting effect and profoundly impact on the health status throughout adult life, likely mediated through epigenetic mechanisms $[7,8]$. These poor health outcomes not only include psychological disorders $[9,10]$ but also several somatic pathologies $[11,12]$.

Very few research on the early-life environment effect on the risk of endometriosis has been published. Intrauterine exposure to diethylstilbestrol is reported to be associated with elevated risk of endometriosis [13], while intrauterine exposure to smoking is reported to be associated with the reduced risk [14]. Preterm birth, formula feeding [15], and regularly fed soy formula in infancy [16] are found to increase the risk. Only one study reported, somewhat tangentially, the link between non-nutritional ELA and endometriosis: childhood physical abuse is reported to be associated with endometriosis [17].

The scarcity of such research is attributable, perhaps in no small amount, to various challenges in conducting such studies. However, exploring the impact of ELA using animal models may be feasible, and the resultant outcome may help us to gain better understanding on such an impact, if any, on endometriosis and perhaps also gain much needed mechanistic insight, which is otherwise difficult for human studies.

A growing body of evidence indicates that ELA, such as physical or sexual abuse, neglect, and loss of a parent, exerts its long-term detrimental effect on health through sensitization or enhanced vulnerability to subsequent stressors, likely involving dysregulated stress response [18]. One such stress response system as a possible mechanism underlying stress sensitization is the hypothalamic-pituitary-adrenal (HPA) axis, which undergoes protracted development throughout childhood and adolescence and may be particularly vulnerable to ELA [19].

Early maternal separation (MS), an ELA animal model, has been widely used to investigate prolonged effects of ELA on neurobiological and behavioral outcomes in adulthood [20]. Prolonged MS results in the hyperreactivity of the HPA axis in adulthood and lasts for life [20]. MS in rodents also induces a greater susceptibility of the HPA axis to acute stress in adults [21, 22]. Besides depressive-like behavior, MS can lead to anxiety-like behavior and cognitive deficits in adulthood [23], which are known to be stressors.

We and others have previously reported that chronic stress promotes the development of endometriosis in mice [24-26]. This promotional effect is likely to be mediated through the deregulated HPA axis and the systemic activation of the sympatho-adreno-medullary (SAM) axis, which results in subsequent secretion of catecholamines. The surging catecholamines may activate the adrenergic receptor $\beta 2$ (ADRB2) and cAMPresponse element binding protein (CREB) in endometriotic lesions, yielding increased angiogenesis and proliferation in mice with induced endometriosis [24]. In addition, chronic psychogenic stress also induces epigenetic changes in the hippocampus in mice with endometriosis, aside from lesional activation of ADRB2/CREB signaling pathway, facilitating the progression of endometriosis [27].

In this study, we hypothesized that ELA, as manifested by MS, can accelerate the progression of endometriosis in mouse, likely through increased anxiety and depression levels. This study was undertaken to test this hypothesis.

\section{Materials and methods Animals}

Eight female Balb/C mice, in late gestation stage, were purchased from the SLAC Experimental Animal Company (Shanghai, China) and used for this study. Three days after arriving at the experimental animal facility, all mice delivered. Only female newborn pubs, totaling 22, were used in the experiment. These pubs were divided into 2 parts, one with 6 and the other, 16. The 6 pubs were used for the validation experiment that MS can induce anxiety and depression like behaviors in adulthood ( 8 weeks of age). The remaining 16 pubs were used to see whether MS can accelerate the progression of endometriosis. Eleven additional female Balb/C mice, of 7 weeks old, were purchased as donors from the same company. All mice were maintained under controlled conditions with a light/dark cycle of $12 / 12 \mathrm{~h}$ and had access to food and water ad libitum. All experiments were 
performed under the guidelines of the National Research Council's Guide for the Care and Use of Laboratory Animals [28] and approved by the institutional experimental animals review board of Shanghai OB/GYN Hospital, Fudan University.

\section{Maternal separation and experimental design}

Twenty-two newborn female Balb/C pubs were randomly divided into two equal-sized groups: the nonseparated (NS) group and the MS group. Designating the day of delivery as postnatal day (PND) 0 , pups in the MS group were separated from their respective dams for $3 \mathrm{~h}$ daily from PND 1 to PND 21 [29]. The pups were then returned to their mothers after $3 \mathrm{~h}$ of MS. In the NS group, the pups were left with their respective dams undisturbed, as usual [29]. At PND 21, the pups were weaned and transferred to new cages with 3-5 animals per cage. They were left undisturbed, and were under routine animal care [29]. In adulthood (8-week old), 3 mice in each group were randomly selected for evaluating the levels of depression and anxiety via several behavioral tests, including forced swimming test, tail suspension test and open field test. The remaining 8 mice in each group procedure to induce endometriosis through injection of uterine fragments. Four weeks after the induction, all mice were sacrificed and their endometriotic lesions were excised for quantification and then prepared for immunohistochemistry analysis. Before the induction and sacrifice, hotplate test was carried out.

\section{Induction of endometriosis}

We used an established mouse model of endometriosis by intraperitoneal (i.p.) injection of endometrial fragments as described [30-32] and also used in our previous studies [24, 33]. Briefly, donor mice were initially injected with $100 \mu \mathrm{g} / \mathrm{kg}$ estradiol benzoate (Animal Medicine Factory, Hangzhou, China). One week later they were sacrificed and their uteri were removed and harvested. The uterine tissues were seeded in a Petri dish containing warm sterile saline, and split longitudinally with a pair of scissors.

Two uterine horns from each mouse were first minced with scissors, ensuring that the maximal diameter of the fragment was consistently smaller than $1 \mathrm{~mm}$. Then uterine fragments were intraperitoneally injected to recipient mice. Thus each mouse received the suspension derived from a half uterus. To eliminate any potential bias, endometrial fragments from 1 donor mice were mixed together and injected i.p. to 2 mice, one each from the two groups. By this approach, any individual variation was minimized.

\section{Behavior tests}

The forced swimming test (FST) and tail suspension test (TST) were performed to measure depression related behaviors in rodents. The open field test (OFT) was performed to measure anxiety-related behaviors.

\section{Forced swimming test (FST)}

The procedure was carried out following previously reported procedures [34, 35]. Each mouse was placed individually into glass cylinders (height $25 \mathrm{~cm}$, diameter 10 $\mathrm{cm}$ ) containing $10 \mathrm{~cm}$ of water at $23-25^{\circ} \mathrm{C}$. The animals were left in the cylinder for $6 \mathrm{~min}$. The total duration of immobility was recorded during the last 4 min of the 6min long testing period. The mouse was judged to be immobile when it ceased struggling and remained floating motionless in the water, making only those movements necessary to keep its head above the water level. The immobility time was scored in real time by two observers who were blinded to the grouping. The results obtained in FST were presented as the arithmetic mean of the immobility time of animals given in seconds for each experimental group.

\section{Tail suspension test (TST)}

The procedure was carried out according to the method as described previously $[34,36]$. In this test, the mouse was suspended from its tail for a fixed time period and its movements were recorded. The ratio between immobility and agitation determines the depressive state of the animal [36].

Briefly, each mouse was individually suspended by the tail to a vertical bar in a wooden box $(30 * 30 \mathrm{~cm})$. The animals were fastened by means adhesive tape fixed 2 $\mathrm{cm}$ from the end of the tail for $6 \mathrm{~min}$. The total duration of immobility was recorded during the last $4 \mathrm{~min}$ of the 6-min long testing period. The mouse was judged to be immobile when it ceased moving its limbs and body, making only those movements necessary to breathe. The immobility time was scored in real time by two observers who were blinded to the grouping. The results obtained in TST were presented as the arithmetic mean of the immobility time of animals given in seconds for each experimental group.

\section{Open field test}

The procedure was carried out according to the method as described previously [37]. Mice were placed into the center of a Plexiglas box $(50 \mathrm{~cm} \times 50 \mathrm{~cm} \times 40 \mathrm{~cm})$ in a brightly lit room. During a 5 -min session, animals were scored for the number of rearing. Animal behavior was recorded and subsequently analyzed using a videotracking system (Shanghai Mobile Datum Information Technology Company, Shanghai, China). 


\section{Hotplate test}

The hotplate test was performed with a commercially available Hot Plate Analgesia Meter (Model BME-480, Institute of Biomedical Engineering, Chinese Academy of Medical Sciences, Tianjin, China) as reported previously [38]. The hotplate consisted of a metal plate of 26 $\mathrm{cm} \times 26 \mathrm{~cm}$, and its surface was heated to a constant temperature of $55.0^{\circ} \mathrm{C} \pm 0.1^{\circ} \mathrm{C}$. A plastic cylinder $(22 \mathrm{~cm}$ in diameter, $12 \mathrm{~cm}$ in height) was placed on the hotplate. Mice were brought to the testing room and allowed to acclimatize for $10 \mathrm{~min}$ before the test. The latency to respond to thermal stimulus is defined as the time (in seconds) elapsed from the moment when the mouse is inserted into the cylinder until it licks its hind paws, or jolted or jumped off the hot plate. Each mouse was tested only once in each session.

\section{Immunohistochemistry}

Tissue samples were fixed in $4 \%(\mathrm{w} / \mathrm{v})$ paraformaldehyde and paraffin-embedded. Serial $4-\mu \mathrm{m}$ sections were obtained from each block, with the first resultant slide being hematoxylin-eosin staining stained to confirm pathologic diagnosis, and the subsequent slides stained for ADRB2, dopamine D2 receptor (DRD2), $\alpha$-smooth muscle actin ( $\alpha$-SMA), CD31 (for microvessel density or MVD), E-cadherin (for epithelial cells), as well as Masson trichrome staining.

Routine deparaffinization and rehydration procedures were performed. For antigen retrieval, the slides were heated at $98{ }^{\circ} \mathrm{C}$ in a citrate buffer (pH 6.0) for a total of 30 min for staining for $\alpha$-SMA, E-cadherin, DRD2, or in an EDTA buffer ( $\mathrm{pH}$ 8.0, Shanghai Sun BioTech Company, Shanghai, China) for a total of $20 \mathrm{~min}$ for staining for ADRB2, CD31, and then cooled naturally to the room temperature. The primary antibodies against ADRB2, DRD2, $\alpha$-SMA, CD31, E-cadherin were diluted to $1: 50,0.5 \mu \mathrm{g} / \mathrm{ml}, 1: 100,1: 50,1: 400$, respectively, and sections were incubated with the primary antibody overnight at $4{ }^{\circ} \mathrm{C}$. After slides were rinsed, the HRP labeled secondary antibody Detection Reagent (Sunpoly-HII, BioSun Technology Co., Ltd., Shanghai, China) was incubated at room temperature for $30 \mathrm{~min}$. The bound antibody complexes were stained for 3-5 min or until appropriate for microscopic examination with diaminobenzidine and then counterstained with hematoxylin $(30 \mathrm{~s})$ and mounted. The names of primary antibodies, along with their vendor names and the concentrations used in this study are listed in Table 1.

Images were obtained with the microscope (Olympus BX51, Olympus, Tokyo, Japan) fitted with a digital camera (Olympus DP70, Olympus). For other immunostained markers, quantification was made through 3-5 randomly selected images for each mouse at 400X magnification were taken to obtain a mean optional density
Table 1 List of names and catalog numbers of antibodies used in this study

\begin{tabular}{llll}
\hline Antibody name & Company & Catalog number & Concentration \\
\hline ADRB2 & Abcam & ab61778 & $1: 50$ \\
DRD2 & Thermo Fisher & PA5-79169 & $0.5 \mu \mathrm{g} / \mathrm{ml}$ \\
a-SMA & Abcam & ab5694 & $1: 100$ \\
CD31 & Abcam & ab28364 & $1: 50$ \\
E-cadherin & CST & $\# 3195$ & $1: 400$ \\
\hline
\end{tabular}

value by Image Pro-Plus 6.0 (Media Cybernetics, Inc., Bethesda, MA, USA), as reported previously.

Human brain, mouse brain, mouse liver tissue and human breast cancer were used as positive controls for ADRB2, DRD2, $\alpha$-SMA, CD31, E-cadherin. For negative controls, mouse ectopic endometrium tissue samples were incubated with rabbit or mouse serum instead of primary antibodies.

To minimize potential bias, the person who evaluated the slides was blinded as to which group the slides belonged to.

\section{Masson trichrome staining}

For Masson trichrome staining, tissue sections were deparaffinized in xylene and rehydrated in a graded alcohol series and then were immersed in Bouin solution at $37{ }^{\circ} \mathrm{C}$ for $2 \mathrm{~h}$. Bouin solution was made with $75 \mathrm{~mL}$ of saturated picric acid, $25 \mathrm{~mL}$ of $10 \%$ formalin $(\mathrm{w} / \mathrm{v})$ solution, and $5 \mathrm{~mL}$ of acetic acid. Tissue sections were stained using the Masson Trichrome Staining kit (Baso, Wuhan, China) following the manufacturer's instructions. The areas of the collagen fiber layer stained in blue in proportion to the entire field of the ectopic implants were calculated by the Image Pro-Plus 6.0 (Media Cybernetics).

\section{Statistical analysis}

The comparison of distributions of all three behavior tests between the two groups was made using the twogroup comparison Student's t-test. Since the sample size was small ( $n=3$ in each group) and the normality assumption was unlikely to hold, a permutation test was also used based on $10^{6}$ permutations. The two-group comparison for hotplate latency and immunostaining levels was made using Wilcoxon's test. $P$ values of less than 0.05 were considered statistically significant. All computations were made with R 3.6.2 [39].

\section{Results}

Neonatal maternal separation elevates anxiety and depression levels in adult mice

We first evaluated as whether there is any behavioral change in the adult mice exposed to MS, and found significant changes. Specifically, in the forced swimming 

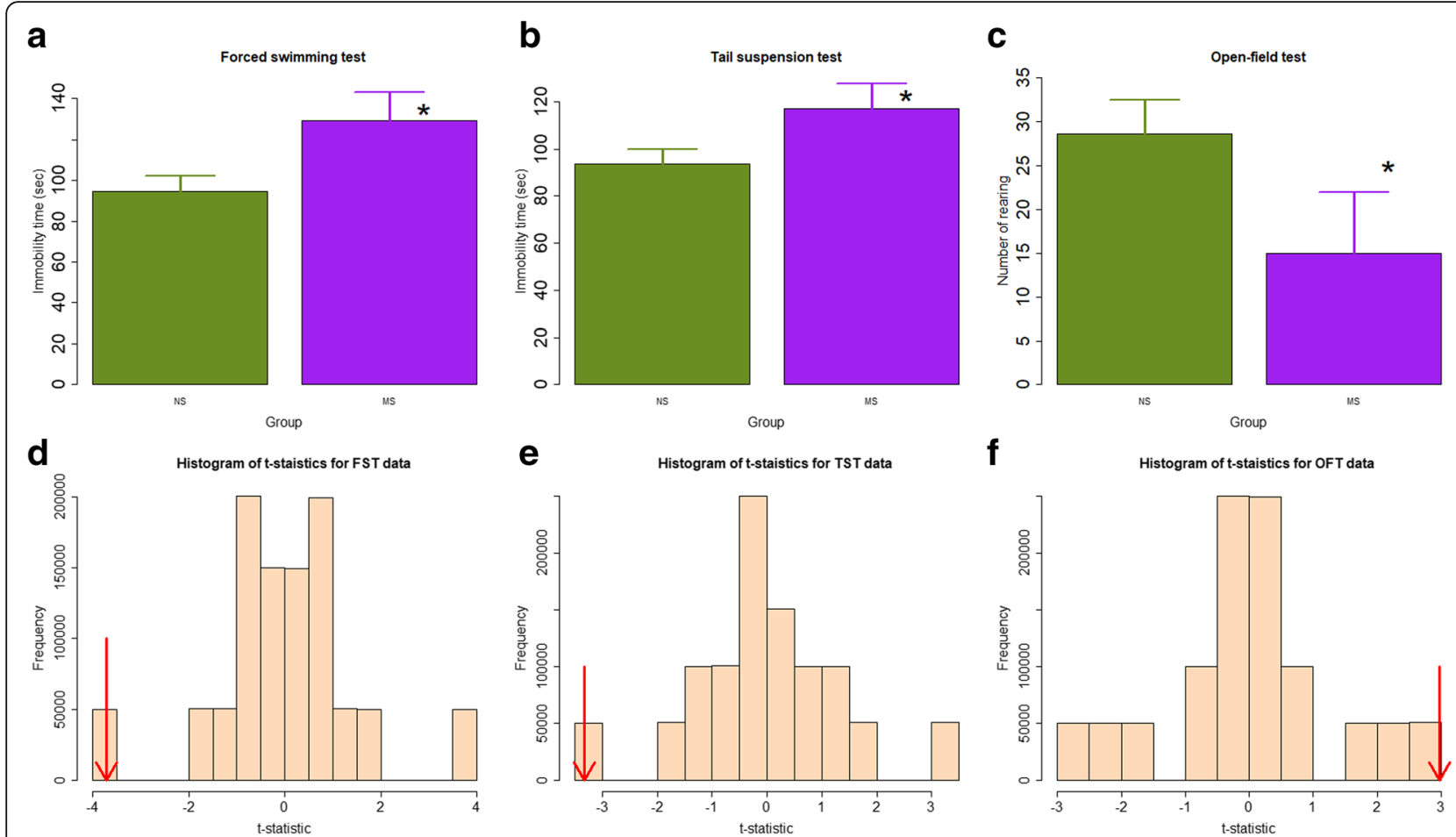

Fig. 1 Summary of behavioral test results. a Difference in mean immobility time of the forced swimming test; $\mathbf{b}$ Mean immobility time of the tail suspension test, and $\mathbf{c}$ Average rearing number of mice in the open field test between the two groups. $n=3$ in each group. NS: non-separated; MS: maternal separation. Data are presented in mean \pm SD. Symbols for the statistical significance level: *: $p<0.05 ;$ \#: $p=0.057$. Permutation test results, based on one million permutations, for the t-statistics for the data of forced swimming test (d), tail suspension test (e), and open field test (f). The red arrows indicate the calculated t-statistic for the original data

test, the mean immobility time of mice in the MS group was significantly longer than that of the NS mice $(129.0 \pm 14.2$ vs. $94.7 \pm 7.4 \mathrm{~s}, p=0.034$; Fig. 1a). Consistently, in the tail suspension test, the mean immobility time of MS mice was also significantly longer than the NS mice $(117.0 \pm 10.5$ vs. $93.7 \pm 6.0 \mathrm{~s}, p=0.041$; Fig. $1 \mathrm{~b})$. In contrast, in the open field test, the average rearing number of the MS mice was marginally significantly less than that of NS mice ( $28.7 \pm 7.0$ vs. $15.0 \pm 3.8, p=0.057$; Fig. 1c). Permutation test indicated that the results were all statistically significant (all $p$-values $<0.05$; Fig. $1 \mathrm{~d}$-f). Taken together, these data collectively indicate that mice in the MS group exhibit more signs of depression as compared with NS mice.

\section{MS promotes the development of endometriosis and exacerbates generalized hyperalgesia in adult mice}

We found that lesions harvested from the mice in the MS group were conspicuously larger than that from NS mice (Fig. 2a), and the total lesion weight was significantly increased as compared with the NS mice $(p<$ 0.007; Fig. 2b). In fact, the mean lesion weight in MS mice increased more than 2 folds as compared with NS mice $(196.4 \pm 87.5 \mathrm{mg}$ vs $87.6 \pm 49.0 \mathrm{mg}$, or an increase by $124.3 \%)$.
There was no statistically significant difference in hotplate latency between the MS and NS mice before the induction of endometriosis $(p>0.05)$. Four weeks after the induction, the hotplate latency was significantly reduced as the result of endometriosis $\left(p=6.1 \times 10^{-5}\right)$. However, mice in the MS group had significantly more reduction in latency as compared with that of NS mice $(p=0.0499$; Fig. 2c).

\section{MS increases ADRB2 staining, microvessel density and the extent of lesional fibrosis}

We next examined immunoreactivity against ADRB2, DRD2, $\alpha$-SMA, CD31-stained MVD, E-cadherin, along with the extent of fibrosis via Masson trichrome staining, in all lesions from mouse with induced endometriosis. As shown in Fig. 3, ADRB2, DRD2 and E-cadherin immunoreactivity was seen primarily in glandular epithelial cells and was localized in the cytoplasm. Aside from smooth muscle cells, $\alpha$-SMA staining was also observed in the cytoplasm of both epithelial cells and stromal cells. In contrast, CD31 immunostaining was seen mostly in vascular endothelial cells (Fig. 3).

We found that MS resulted in significantly higher staining of ADRB2 and $\alpha$-SMA $(p=0.0002$, and $p=$ 0.0019 , respectively; Fig. 4a,e) but significantly lower 


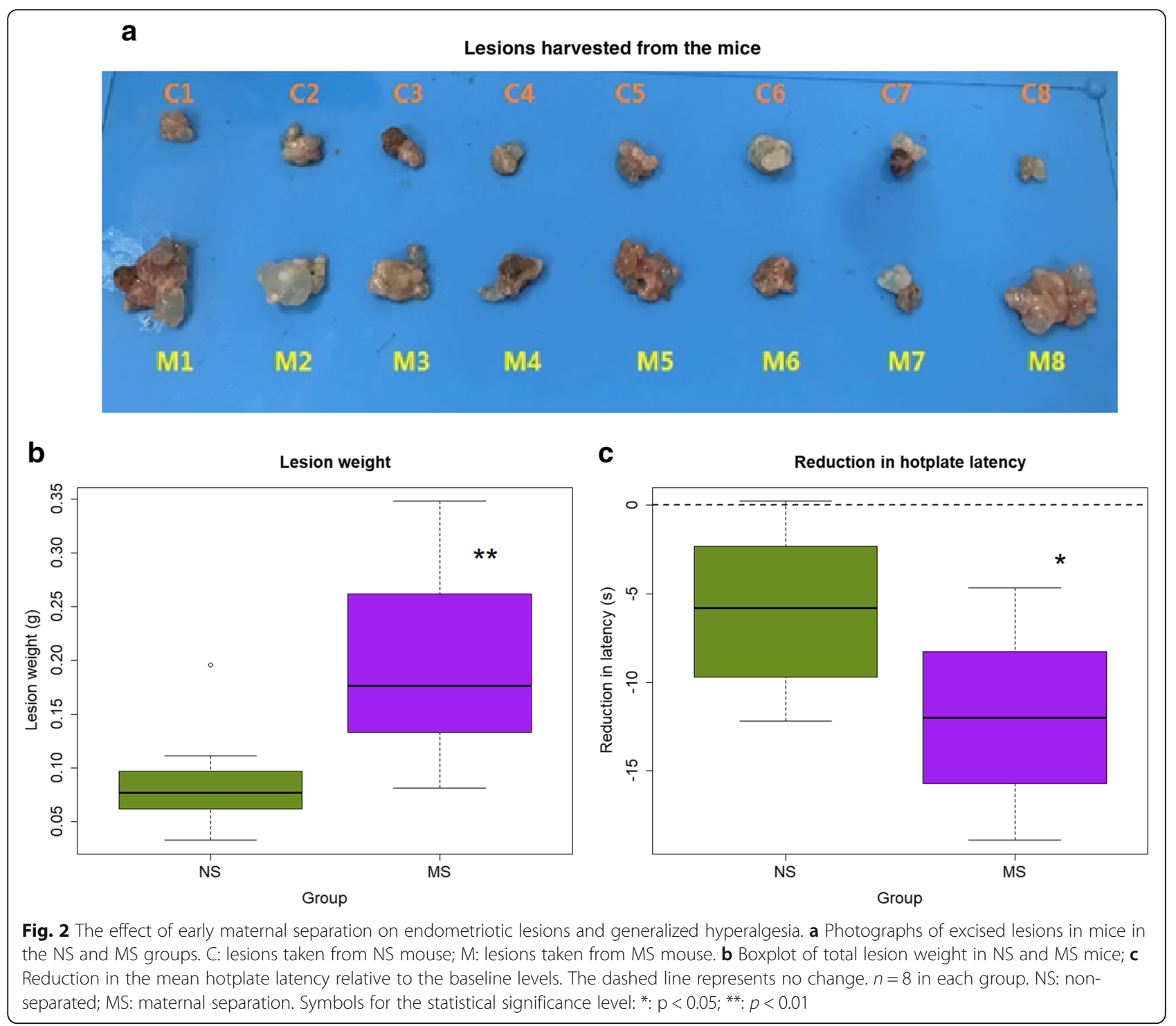

staining of DRD2 and E-cadherin (both p's $=0.0002$; Fig. $4 \mathrm{~b}, \mathrm{~d})$ in ectopic endometrium as compared with NS mice. Consistent with the increased lesion size, MS yielded significantly higher MVD ( $p=0.0009$; Fig. 4c) and more fibrotic content ( $p=0.0002$; Fig. 4f).

The lesional ADRB2 and DRD2 staining levels were closely correlated $(\mathrm{r}=-0.76, p=0.0006)$. Both were correlated closely with the lesional MVD $(\mathrm{r}=0.81, p=0.0001$, and $\mathrm{r}=-0.68, p=0.004$, respectively). While the lesion weight correlated marginally with the reduction in hotplate latency $(\mathrm{r}=-0.50, p=0.055)$, the extent of lesional fibrosis correlated significantly $(\mathrm{r}=-0.55, p=0.029)$.

\section{Discussion}

In this study, we first confirmed that MS during infancy results in anxiety and depression-like behaviors in mouse, just as reported extensively [40, 41]. In addition, we have shown that MS promotes the development of endometriosis and exacerbates endometriosis-associated generalized hyperalgesia in adult female mice, likely through decreased DRD2 expression and activation of the ADRB2/CREB signaling pathway, leading to increased angiogenesis and progression of endometriotic lesions.

Severe adversity induced psychological stresses, such as bereavement, in early life have been reported to be associated with accelerated development of certain malignancies [42, 43]. Although such data are lacking for endometriosis, one study has reported that childhood physical abuse is associated with risk of developing endometriosis [17], suggesting that ELAaccelerated lesional progression is biologically plausible, especially given that retrograde menstruation is nearly universal and is likely the cause for 


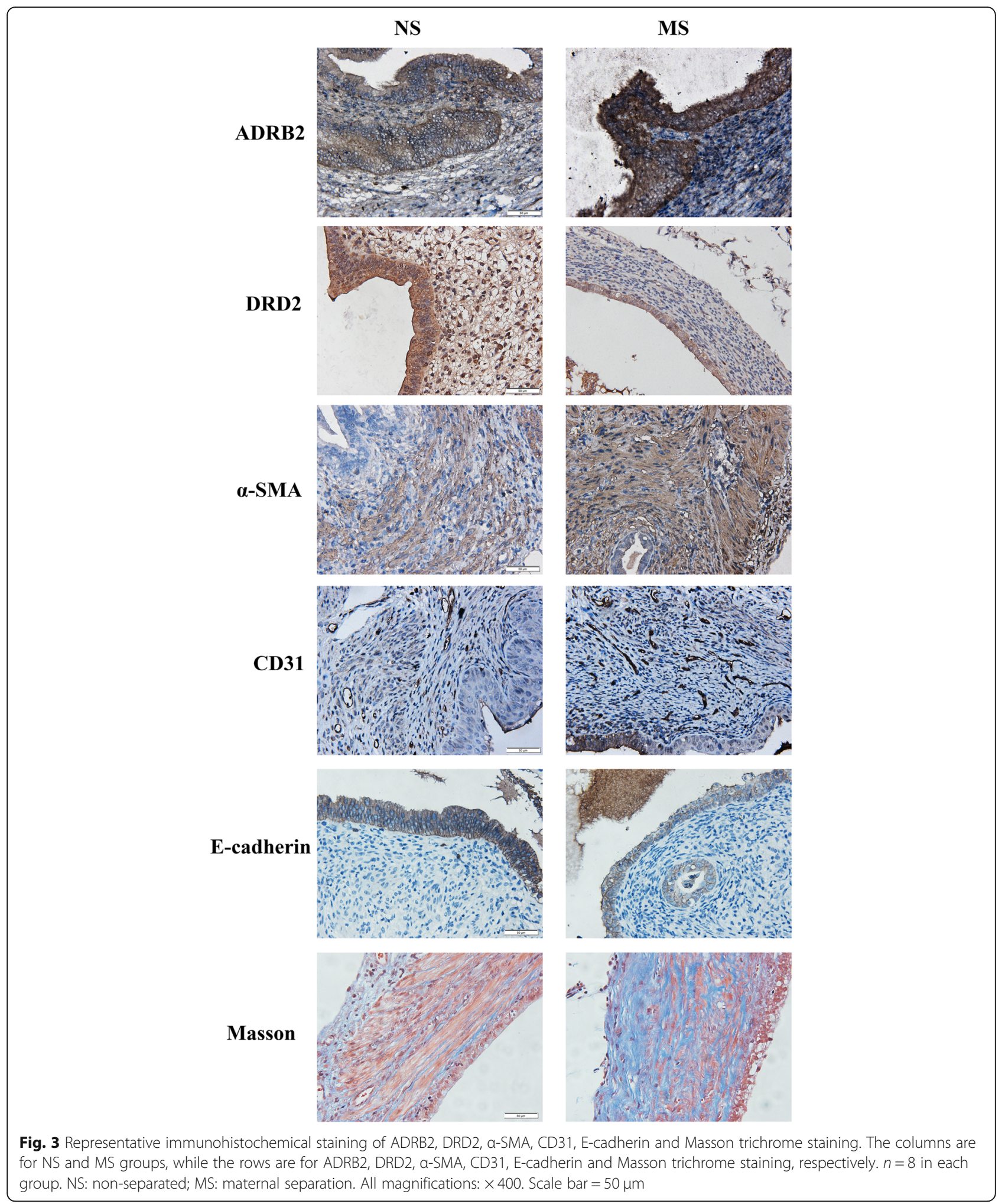

endometriosis [44]. Thus, a recent proposition that trauma, physical or otherwise, increases the risk of endometriosis [45] may have some merits. Unfortunately, the impact of non-nutritional ELA on the risk of endometriosis is essentially undocumented and warrants more research. By demonstrating that MS, as a form of ELA, can accelerate the progression of endometriosis, this study provided, to our best 


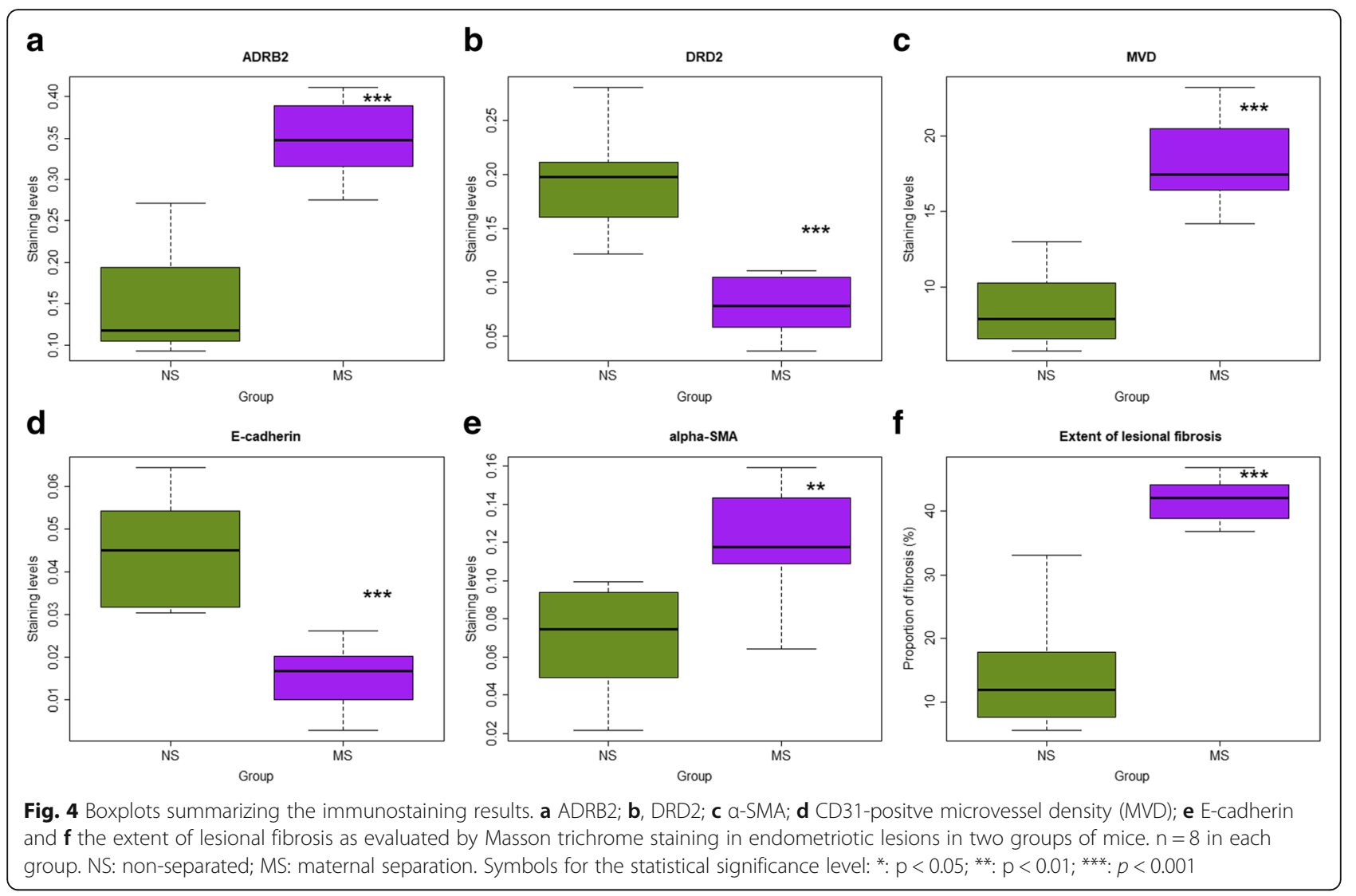

knowledge, the first piece of experimental evidence for the promotional effect of ELA on the development of endometriosis in adulthood.

Our study is consistent with the reports that MS results in significantly higher levels of anxiety and depression [46, 47]. Anxiety and depression are both potent stressors. The increased levels of anxiety and depression in mice are unmistakable sign of chronic stress. Consequently, they are likely to induce systemic activation of the HPA and the SAM axes, resulting in increased release of glucocorticoids and catecholamines, inducing the activation of the ADRB2 and CREB signaling pathways and accelerating lesional progression in mice with induced endometriosis [24, 33]. In addition, endometriosis, in and by itself, can also induce pain, anxiety and depression [48], virtually establishing a feed-forward loop that further promotes lesional progression.

We have previously shown that endometriotic lesions are fundamentally wounds undergoing repeated tissue injury and repair (ReTIAR) $[49,50]$ due to their cardinal hallmark of cyclic bleeding [51]. As a result, the endometriotic lesions undergo epithelialmesenchymal transition (EMT) and fibroblast-tomyofibroblast transdifferentiation (FMT), resulting in increased collagen production and ultimately fibrosis $[52,53]$. In addition, endometriotic stromal cells are differentiated into smooth muscle cells (SMCs), leading to smooth muscle metaplasia (SMM) that is frequently seen in endometriotic lesions [54-57].

In mice exposed to MS, their lesions showed reduced $E$-cadherin staining but increased staining of $\alpha$-SMA in lesions as compared with NS mice, along with more extensive fibrosis. These results indicate that endometriotic lesions in MS mice experienced more complete and thorough EMT and FMT, leading to greater fibrotic content---evidence for accelerated lesional progression.

This acceleration is likely due to the activation of the ADRB2/CREB signaling pathway. Endometriotic lesions in both mouse and humans express ADRB2 but DRD2 staining is reduced [27, 33]. Consequently, catecholamines, such as epinephrine and norepinephrine, resulting from chronic stress would activate the cAMP/ protein kinase A (PKA) signaling pathway, which in turn results in the phosphorylation of the CREB family [58] that is known to be involved in steriodogenesis in endometriosis [59]. PKA may also cross-regulate NF- $\mathrm{kB}$ [60], which is also known to play a critical role in the development of endometriosis [61].

Given that natural killer (NK) cells are known to express adrenergic receptors, it has been suggested that the sympathetic nervous system (SNS) may impact negatively on NK cytotoxicity and thus tumor metastasis 
[62-64]. Indeed, previous research has demonstrated that MS and chronic stress can impair NK cytotoxicity and hence tumor immunity [65]. In endometriosis, the impaired NK cell cytotoxicity as well as decreased NK cells in peritoneal fluid and sera have been noted since early 1990s [66-69]. Given the apparent elevated levels of anxiety and depression and the dysregulation of the HPA axis in mice exposed to MS, the presumed decrease in NK cytotoxicity would diminish the removal of endometriotic tissues, permitting their survival, implantation and proliferation. As such, the impaired NK cell function may also play a role in MS-accelerated lesional progression [70, 71].

ELA such as MS has been demonstrated to induce long-term changes in the central nervous system (CNS) in rodents, including those parts that modulate the integration of pain [72]. Rats exposed to MS are predisposed to develop visceral hyperalgesia, reduced somatic analgesia, and increased colonic motility in response to an acute psychological stressor, mimicking the cardinal features of irritable bowel syndrome [73]. The altered neuronal wiring and increased sensitivity to noticeptive stimuli would potentially exacerbate or intensify endometriosis-associated pain and thus further activate the HPA/SMA axes, forming another vicious cycle and thus promoting lesional progression. Our study has several strengths. First, we validated the finding that MS results in anxiety and depression-like behavior, which, in conjunction with lesional expression of ADRB2 and DRD2, provides evidence that HPA/SMA axes are involved. Second, we stained markers of EMT and FMT and also evaluated the extent of lesional fibrosis, which are known to be milestones of lesional progression [74].

Our study also has several limitations. First, we did not provide any mechanistic evidence as why MS accelerates endometriosis. This should await further investigations. Second, we only demonstrated MS instituted during PND 1-21 accelerates the progression of endometriosis. We did not identify which period in the infancy is the most critical or vulnerable, nor did we identify the minimal length of MS that is necessary to promote endometriosis progression. Future research is warranted to illuminate these issues. Hopefully, our study can pique the interest in this line of research, in particular in humans. Lastly, our study did not address a very important question as whether there may be ways to rectify the negative impact of ELA. Given that early MS led to anxiety and depression-like behavior in adulthood and that inflammation plays a critical role in depression $[75,76]$, one possible intervention might be to boost proresolving response through lipid mediators such as resolvins and lipoxin A4 [77]. Indeed, both resolvings and lipoxin A4 have been reported to suppress progression of endometriosis in rodent models [7880]. Future studies are needed to further explore this line of research.

\section{Conclusions}

In summary, this study demonstrates that exposure of female mouse pups to stress such as MS during their infancy period alters the activity of HPA axis and increases depression as well as anxiety levels in adulthood. More importantly, it demonstrates that ELA accelerates the progression of endometriosis, possibly through altered neuronal wiring and hyperactivity of the HPA axis.

\section{Supplementary information}

Supplementary information accompanies this paper at https://doi.org/10. 1186/s12958-020-00600-4.

Additional file 1: Supplementary Figure S1. Positive control and negative control for immunohistochemical staining. All magnifications: $\times$ 400. Scale bar $=50 \mu \mathrm{m}$.

\section{Abbreviations}

a-SMA: $a$-smooth muscle actin; ADRB2: Adrenergic receptor $\beta 2$; CREB: CAMPresponse element binding protein; CNS: Central nervous system;

DOHaD: Developmental origin of adult health and disease; DRD2: Dopamine D2 receptor; ELA: Early-life adversity; EMT: Epithelial-mesenchymal transition; FMT: Fibroblast-to-myofibroblast transdifferentiation.; FST: Forced swimming test; HPA: Hypothalamic-pituitary-adrenal; MS: Maternal separation; MVD: Microvessel density; NK: Natural killer; NS: Non-separated; OFT: Open field test; PND: Postnatal day; SMA: Sympatho-adreno-medullary; SMC: Smooth muscle cell; SNS: Sympathetic nervous system; TST: Tail suspension test

\section{Conflict of interest}

None of the authors report any conflict of interest.

\section{Authors' contributions}

S.W.G. conceived and designed the study, performed data analysis and data interpretation, and drafted the manuscript. Q.L. performed all the experiments and carried out data analysis. X.L. was involved in the data interpretation and discussion. All participated in the writing and approved the final version of the manuscript.

\section{Funding}

This research was supported in part by grants 81530040 (SWG), 81771553 (SWG), and 81671436 (XSL) from the National Science Foundation of China, and an Excellence in Centers of Clinical Medicine grant (2017ZZ01016) from the Science and Technology Commission of Shanghai Municipality.

\section{Availability of data and materials}

The dataset used in current study is available from the corresponding author on reasonable request.

\section{Ethics approval and consent to participate}

All experiments were performed under the guidelines of the National Research Council's Guide for the Care and Use of Laboratory Animals and approved by the institutional experimental animals review board of Shanghai OB/GYN Hospital, Fudan University.

\section{Consent for publication}

Not applicable.

Competing interests

All authors declare that they have no competing interests. 


\section{Author details}

'Shanghai Obstetrics and Gynecology Hospital, Fudan University, Shanghai 200090, China. ${ }^{2}$ Shanghai Key Laboratory of Female Reproductive Endocrine-Related Diseases, Fudan University, Shanghai, China. ${ }^{3}$ Shanghai Obstetrics and Gynecology Hospital, Fudan University Shanghai College of Medicine, 419 Fangxie Road, Shanghai 200011, China.

\section{Received: 9 March 2020 Accepted: 24 April 2020}

\section{Published online: 12 June 2020}

\section{References}

1. Vercellini P, Vigano P, Somigliana E, Fedele L. Endometriosis: pathogenesis and treatment. Nat Rev Endocrinol. 2014;10:261-75.

2. Lagana AS, La Rosa VL, Rapisarda AMC, Valenti G, Sapia F, Chiofalo B, et al. Anxiety and depression in patients with endometriosis: impact and management challenges. Int J Women's Health. 2017;9:323-30.

3. Vigano P, Parazzini F, Somigliana E, Vercellini P. Endometriosis: epidemiology and aetiological factors. Best Pract Res Clin Obstet Gynaecol. 2004:18:177-200.

4. Barker DJ. Childhood causes of adult diseases. Arch Dis Child. 1988;63:867-9.

5. Eriksson JG. Developmental origins of health and disease - from a small body size at birth to epigenetics. Ann Med. 2016;48:456-67.

6. Hanson MA, Gluckman PD. Developmental origins of health and disease-global public health implications. Best Pract Res Clin Obstet Gynaecol. 2015; 29:24-31.

7. Felitti VJ, Anda RF, Nordenberg D, Williamson DF, Spitz AM, Edwards V, et al. Relationship of childhood abuse and household dysfunction to many of the leading causes of death in adults. The adverse childhood experiences (ACE) study. Am J Prev Med. 1998;14:245-58.

8. Szyf M, Meaney MJ. Epigenetics, behaviour, and health. Allergy Asthma Clin Immunol. 2008;4:37-49.

9. Vaiserman AM, Koliada AK. Early-life adversity and long-term neurobehavioral outcomes: epigenome as a bridge? Hum Genomics. 2017;11:34.

10. Maccari S, Polese D, Reynaert ML, Amici T, Morley-Fletcher S, Fagioli F. Early-life experiences and the development of adult diseases with a focus on mental illness: the human birth theory. Neuroscience. 2017; 342:232-51.

11. Seckl JR, Meaney MJ. Early life events and later development of ischaemic heart disease. Lancet. 1993;342:1236.

12. Davis DA, Luecken $L$, Zautra AJ. Are reports of childhood abuse related to the experience of chronic pain in adulthood? A meta-analytic review of the literature. Clin J Pain. 2005;21:398-405.

13. Missmer SA, Hankinson SE, Spiegelman D, Barbieri RL, Michels KB, Hunter DJ. In utero exposures and the incidence of endometriosis. Fertil Steril. 2004:82:1501-8.

14. Buck Louis GM, Hediger ML, Pena JB. Intrauterine exposures and risk of endometriosis. Hum Reprod. 2007;22:3232-6..

15. Vannuccini S, Lazzeri L, Orlandini C, Tosti C, Clifton VL, Petraglia F. Potential influence of in utero and early neonatal exposures on the later development of endometriosis. Fertil Steril. 2016;105:997-1002.

16. Upson K, Sathyanarayana S, Scholes D, Holt VL. Early-life factors and endometriosis risk. Fertil Steril. 2015;104:964-71 e5.

17. Tietjen GE, Brandes JL, Peterlin BL, Eloff A, Dafer RM, Stein MR, et al. Childhood maltreatment and migraine (part III). Association with comorbid pain conditions. Headache. 2010;50:42-51.

18. Hammen C, Henry R, Daley SE. Depression and sensitization to stressors among young women as a function of childhood adversity. J Consult Clin Psychol. 2000;68:782-7.

19. Tarullo AR, Gunnar MR. Child maltreatment and the developing HPA axis. Horm Behav. 2006;50:632-9.

20. Vetulani J. Early maternal separation: a rodent model of depression and a prevailing human condition. Pharmacol Rep. 2013;65:1451-61.

21. Nishi M, Horii-Hayashi N, Sasagawa T. Effects of early life adverse experiences on the brain: implications from maternal separation models in rodents. Front Neurosci. 2014;8:166.

22. Shu C, Xiao L, Tang J, Wang G, Zhang X, Wang X. Blunted behavioral and molecular responses to chronic mild stress in adult rats with experience of infancy maternal separation. Tohoku J Exp Med. 2015;235:81-7.

23. Huot RL, Plotsky PM, Lenox RH, MCNamara RK. Neonatal maternal separation reduces hippocampal mossy fiber density in adult Long Evans rats. Brain Res. 2002;950:52-63.
24. Long Q, Liu X, Qi Q, Guo SW. Chronic stress accelerates the development of endometriosis in mouse through adrenergic receptor beta2. Hum Reprod. 2016;31:2506-19.

25. Appleyard CB, Cruz ML, Hernandez S, Thompson KJ, Bayona M, Flores I. Stress management affects outcomes in the pathophysiology of an endometriosis model. Reprod Sci. 2015;22:431-41.

26. Cuevas M, Flores I, Thompson KJ, Ramos-Ortolaza DL, Torres-Reveron A, Appleyard CB. Stress exacerbates endometriosis manifestations and inflammatory parameters in an animal model. Reprod Sci. 2012;19:851-62.

27. Guo SW, Zhang Q, Liu X. Social psychogenic stress promotes the development of endometriosis in mouse. Reprod BioMed Online. 2017;34: 225-39.

28. Council NR. Guide for the care and use of laboratory animals. Washington, DC: National Academies Press; 1996.

29. Melo C, Vizin RCL, Silva NU, Ishikawa DT, Echeverry MB, Carrettiero DC, et al. Early maternal separation promotes alterations in the thermoregulatory profile of adult Wistar rats. J Therm Biol. 2018;78:151-60.

30. Somigliana E, Vigano P, Rossi G, Carinelli S, Vignali M, Panina-Bordignon P. Endometrial ability to implant in ectopic sites can be prevented by interleukin-12 in a murine model of endometriosis. Hum Reprod. 1999;14: 2944-50.

31. Somigliana E, Vigano P, Filardo P, Candiani M, Vignali M, Panina-Bordignon P. Use of knockout transgenic mice in the study of endometriosis: insights from mice lacking beta(2)-microglobulin and interleukin-12p40. Fertil Steril. 2001;75:203-6.

32. Bacci M, Capobianco A, Monno A, Cottone L, Di Puppo F, Camisa B, et al. Macrophages are alternatively activated in patients with endometriosis and required for growth and vascularization of lesions in a mouse model of disease. Am J Pathol. 2009;175:547-56.

33. Long Q, Liu X, Guo SW. Surgery accelerates the development of endometriosis in mice. Am J Obstet Gynecol. 2016;215:320 e1-e15.

34. Poleszak E, Szopa A, Wyska E, Kukula-Koch W, Serefko A, Wosko S, et al. Caffeine augments the antidepressant-like activity of mianserin and agomelatine in forced swim and tail suspension tests in mice. Pharmacol Rep. 2016;68:56-61.

35. Porsolt RD, Bertin A, Jalfre M. Behavioral despair in mice: a primary screening test for antidepressants. Arch Int Pharmacodyn Ther. 1977;229: $327-36$.

36. Steru L, Chermat R, Thierry B, Simon P. The tail suspension test: a new method for screening antidepressants in mice. Psychopharmacology. 1985; 85:367-70.

37. Yue N, Huang H, Zhu X, Han Q, Wang Y, Li B, et al. Activation of P2X7 receptor and NLRP3 inflammasome assembly in hippocampal glial cells mediates chronic stress-induced depressive-like behaviors. J Neuroinflammation. 2017:14:102.

38. Lu Y, Nie J, Liu X, Zheng Y, Guo SW. Trichostatin a, a histone deacetylase inhibitor, reduces lesion growth and hyperalgesia in experimentally induced endometriosis in mice. Hum Reprod. 2010;25:1014-25.

39. Team. RC. R: A Language and Environment for Statistical Computing. Vienna: R Foundation for Statistical Computing; 2013.

40. Cui Y, Cao K, Lin H, Cui S, Shen C, Wen W, et al. Early-life stress induces depression-like behavior and synaptic-plasticity changes in a maternal separation rat model: gender difference and metabolomics study. Front Pharmacol. 2020;11:102.

41. Wang $R$, Wang $W$, Xu J, Liu D, Wu H, Qin X, et al. Jmjd3 is involved in the susceptibility to depression induced by maternal separation via enhancing the neuroinflammation in the prefrontal cortex and hippocampus of male rats. Exp Neurol. 2020;328:113254.

42. Momen NC, Olsen J, Gissler M, Cnattingius S, Li J. Early life bereavement and childhood cancer: a nationwide follow-up study in two countries. BMJ Open. 2013;3:e002864.

43. Kennedy B, Valdimarsdottir U, Sundstrom K, Sparen P, Lambe M, Fall K, et al. Loss of a parent and the risk of cancer in early life: a nationwide cohort study. Cancer Causes Control. 2014;25:499-506.

44. Yovich JL, Rowlands PK, Lingham S, Sillender M, Srinivasan S. Pathogenesis of endometriosis: look no further than John Sampson. Reprod BioMed Online. 2019:40:7-11.

45. Canis M, Bourdel N, Houlle C, Gremeau AS, Botchorishvili R, Matsuzaki S. Trauma and endometriosis. A review. May we explain surgical phenotypes and natural history of the disease? J Gynecol Obstet Hum Reprod. 2017:46:219-27. 
46. Lambas-Senas L, Mnie-Filali O, Certin V, Faure C, Lemoine L, Zimmer L, et al. Functional correlates for $5-\mathrm{HT}(1 \mathrm{~A})$ receptors in maternally deprived rats displaying anxiety and depression-like behaviors. Prog NeuroPsychopharmacol Biol Psychiatry. 2009;33:262-8.

47. Rentesi G, Antoniou K, Marselos M, Fotopoulos A, Alboycharali J, Konstandi M. Long-term consequences of early maternal deprivation in serotonergic activity and HPA function in adult rat. Neurosci Lett. 2010;480:7-11.

48. Li T, Mamillapalli R, Ding S, Chang H, Liu ZW, Gao XB, et al. Endometriosis alters brain electrophysiology, gene expression and increases pain sensitization, anxiety, and depression in female mice. Biol Reprod. 2018;99: 349-59.

49. Guo SW, Ding D, Shen M, Liu X. Dating Endometriotic ovarian cysts based on the content of cyst fluid and its potential clinical implications. Reprod Sci. 2015;22:873-83.

50. Zhang Q, Duan J, Olson M, Fazleabas A, Guo SW. Cellular changes consistent with epithelial-mesenchymal transition and fibroblast-tomyofibroblast transdifferentiation in the progression of experimental endometriosis in baboons. Reprod Sci. 2016;23:1409-21.

51. Brosens IA. Endometriosis--a disease because it is characterized by bleeding Am J Obstet Gynecol. 1997;176:263-7.

52. Zhang Q, Duan J, Liu X, Guo SW. Platelets drive smooth muscle metaplasia and fibrogenesis in endometriosis through epithelial-mesenchymal transition and fibroblast-to-myofibroblast transdifferentiation. Mol Cell Endocrinol. 2016;428:1-16.

53. Yan D, Liu X, Guo SW. Nerve fibers and endometriotic lesions: partners in crime in inflicting pains in women with endometriosis. Eur J Obstet Gynecol Reprod Biol. 2017;209:14-24.

54. Itoga T, Matsumoto T, Takeuchi H, Yamasaki S, Sasahara N, Hoshi T, et al. Fibrosis and smooth muscle metaplasia in rectovaginal endometriosis. Pathol Int. 2003;53:371-5.

55. Khare VK, Martin DC, Eltorky M. A comparative study of ovarian and pelvic wall-infiltrating endometriosis. J Am Assoc Gynecol Laparosc. 1996;3:235-9.

56. Matsuzaki S, Darcha C. Involvement of the Wnt/beta-catenin signaling pathway in the cellular and molecular mechanisms of fibrosis in endometriosis. PLoS One. 2013;8:e76808.

57. Mechsner S, Bartley J, Loddenkemper C, Salomon DS, Starzinski-Powitz A, Ebert AD. Oxytocin receptor expression in smooth muscle cells of peritoneal endometriotic lesions and ovarian endometriotic cysts. Fertil Steril. 2005;83(Suppl 1):1220-31.

58. Montminy M. Transcriptional regulation by cyclic AMP. Annu Rev Biochem. 1997;66:807-22.

59. Hsu CC, Lu CW, Huang BM, Wu MH, Tsai SJ. Cyclic adenosine 3',5'monophosphate response element-binding protein and CCAAT/enhancerbinding protein mediate prostaglandin E2-induced steroidogenic acute regulatory protein expression in endometriotic stromal cells. Am J Pathol. 2008;173:433-41.

60. Bierhaus A, Wolf J, Andrassy M, Rohleder N, Humpert PM, Petrov D, et al. A mechanism converting psychosocial stress into mononuclear cell activation. Proc Natl Acad Sci U S A. 2003;100:1920-5.

61. Guo SW. Nuclear factor-kappab (NF-kappaB): an unsuspected major culprit in the pathogenesis of endometriosis that is still at large? Gynecol Obstet Investig. 2007;63:71-97.

62. Ben-Eliyahu S, Shakhar G, Page GG, Stefanski V, Shakhar K. Suppression of NK cell activity and of resistance to metastasis by stress: a role for adrenal catecholamines and beta-adrenoceptors. Neuroimmunomodulation. 2000;8: 154-64.

63. Elenkov IJ, Wilder RL, Chrousos GP, Vizi ES. The sympathetic nerve--an integrative interface between two supersystems: the brain and the immune system. Pharmacol Rev. 2000;52:595-638.

64. Rosenne E, Shakhar G, Melamed R, Schwartz Y, Erdreich-Epstein A, BenEliyahu S. Inducing a mode of NK-resistance to suppression by stress and surgery: a potential approach based on low dose of poly I-C to reduce postoperative cancer metastasis. Brain Behav Immun. 2007;21:395-408.

65. Nakamura T, Walker AK, Sominsky L, Allen T, Rosengren S, Hodgson DM. Maternal separation in early life impairs tumor immunity in adulthood in the F344 rat. Stress. 2011;14:335-43.

66. Garzetti GG, Ciavattini A, Provinciali M, Fabris N, Cignitti M, Romanini C. Natural killer cell activity in endometriosis: correlation between serum estradiol levels and cytotoxicity. Obstet Gynecol. 1993;81:665-8.
67. Kikuchi Y, Ishikawa N, Hirata J, Imaizumi E, Sasa H, Nagata I. Changes of peripheral blood lymphocyte subsets before and after operation of patients with endometriosis. Acta Obstet Gynecol Scand. 1993;72:157-61.

68. Oosterlynck DJ, Cornillie FJ, Waer M, Vandeputte M, Koninckx PR. Women with endometriosis show a defect in natural killer activity resulting in a decreased cytotoxicity to autologous endometrium. Fertil Steril. 1991;56:45-51.

69. Tanaka E, Sendo F, Kawagoe S, Hiroi M. Decreased natural killer cell activity in women with endometriosis. Gynecol Obstet Investig. 1992;34:27-30.

70. Lebovic DI, Mueller MD, Taylor RN. Immunobiology of endometriosis. Fertil Steril. 2001;75:1-10.

71. Du Y, Liu X, Guo SW. Platelets impair natural killer cell reactivity and function in endometriosis through multiple mechanisms. Hum Reprod. 2017;32:794-810.

72. Liu D, Caldji C, Sharma S, Plotsky PM, Meaney MJ. Influence of neonatal rearing conditions on stress-induced adrenocorticotropin responses and norepinepherine release in the hypothalamic paraventricular nucleus. J Neuroendocrinol. 2000;12:5-12.

73. Coutinho SV, Plotsky PM, Sablad M, Miller JC, Zhou H, Bayati Al, et al. Neonatal maternal separation alters stress-induced responses to viscerosomatic nociceptive stimuli in rat. Am J Physiol Gastrointest Liver Physiol. 2002;282:G307-16.

74. Guo SW. Fibrogenesis resulting from cyclic bleeding: the holy grail of the natural history of ectopic endometrium. Hum Reprod. 2018;33:353-6.

75. Fleshner M, Frank M, Maier SF. Danger signals and Inflammasomes: stressevoked sterile inflammation in mood disorders. Neuropsychopharmacology. 2017:42:36-45.

76. Franklin TC, Xu C, Duman RS. Depression and sterile inflammation: essential role of danger associated molecular patterns. Brain Behav Immun. 2018;72: 2-13.

77. Pirault J, Back M. Lipoxin and Resolvin receptors transducing the resolution of inflammation in cardiovascular disease. Front Pharmacol. 2018;9:1273.

78. Kumar R, Clerc AC, Gori I, Russell R, Pellegrini C, Govender L, et al. Lipoxin a(4) prevents the progression of de novo and established endometriosis in a mouse model by attenuating prostaglandin $\mathrm{E}(2)$ production and estrogen signaling. PLoS One. 2014;9:e89742.

79. Wu R, Zhou W, Chen S, Shi Y, Su L, Zhu M, et al. Lipoxin A4 suppresses the development of endometriosis in an ALX receptor-dependent manner via the p38 MAPK pathway. Br J Pharmacol. 2014;171:4927-40.

80. Dmitrieva N, Suess G, Shirley R. Resolvins RvD1 and 17(R)-RvD1 alleviate signs of inflammation in a rat model of endometriosis. Fertil Steril. 2014;102: $1191-6$

\section{Publisher's Note}

Springer Nature remains neutral with regard to jurisdictional claims in published maps and institutional affiliations.

Ready to submit your research? Choose BMC and benefit from:

- fast, convenient online submission

- thorough peer review by experienced researchers in your field

- rapid publication on acceptance

- support for research data, including large and complex data types

- gold Open Access which fosters wider collaboration and increased citations

- maximum visibility for your research: over $100 \mathrm{M}$ website views per year

At BMC, research is always in progress.

Learn more biomedcentral.com/submissions 